\title{
Justice: Let's look beyond the system as we know it
}

\author{
Rick Linden, BA, MA, PhD*
}

The justice system plays a major role in our quest for community safety and well-being. However, it never has been a coherent 'system' committed to achieving just outcomes. Rather, it is a very loosely-articulated group of organizations, many of which often seem more focused on their own respective needs and operations than with the overall goal of building a healthy society. The re-launch of this Journal is timely because it is becoming increasingly obvious that complex societal issues can only be solved by long-term collaboration among organizations both inside and outside of the traditional justice system.

While a broad range of justice-related research will meet the mandate of the Journal of Community Safety and Well-being, two recent news reports raise some current issues that might well be addressed in forthcoming issues of the Journal.

The first of these is that public health agencies in both Toronto and Montreal have recently advocated for the federal government to decriminalize the personal use of all illicit drugs, and that we move to treating drug use as a public health issue, not a criminal one. This view from these health agencies makes the case that addiction is a medical problem and that criminalization creates barriers to the provision of treatment. The threat of criminal charges stigmatizes drug users, and the threat of arrest often makes them reluctant to come forward for treatment.

While the question of decriminalization is complex, few would argue that the so-called "war on drugs" has been anything but an expensive failure. While that term is more associated with the US than it may be to Canada or other countries, most developed nations have similarly favoured interdiction and prosecution, even as illicit drug markets have continued to thrive and expand. Taking a public health approach to the problem would free up an enormous amount of police time and other justice resources (there were nearly 91,000 drug-related offences known to the police in 2017), and would offer the prospect of more effective collaborations that could help users and addicts more readily return to being healthy, safe, and more productive members of society.

Drug offenses are not the only problems that should be treated using a broad collaborative model. The Canadian Association of Police Governance recently asked their members to identify the major issues facing their police services. The top issues cited were 'policing persons with mental issues' and 'domestic violence', both clearly social issues.
Not far behind were 'root causes of homelessness' and 'First Nations issues in urban centres', followed by 'opioid overdoses 'and 'marijuana legalization' (Malloy 2018). It will take a major commitment to research to ensure that evidence is available to help plan and implement what will inevitably be very complex new ways of improving community safety and well-being in all of these areas

The other recent news story addressed what I believe to be a major problem affecting our ability to ensure safer communities. The issue is highlighted in the article's opening sentence: "Amid a summer of gun violence, a Scarborough gang prevention program is closing its doors because its federal funding has run out." Winsa (2018) goes on to describe how, at a time when those responsible for community safety in Toronto are scrambling to find ways of dealing with the guns and gangs issue, this Scarborough program will end in August because its federal funding has ended. The National Crime Prevention Strategy (NCPS) has had a long-standing policy that requires funding to be cut off after five years, even if the program has proven to be successful. The hope has been that other levels of government will pick up the future costs of successful programs, but this rarely happens.

This NCPS policy is certainly not the only reason that successful community safety initiatives are often ephemeral. Even the best initiatives may not survive a change in government, a new police chief, or even the transfer or retirement of a police service member who championed the initiative. One of the first directives of Ontario's new Ford government cited concerns raised by some, including Ontario's police unions, and responded by halting the implementation of improvements to the province's police oversight agencies. While Premier Ford and others claimed that the new oversight mechanisms would reduce public confidence in the police, one needs only to look to the USA to see how a lack of effective oversight has destroyed public trust in the police.

Within the police community, the failure of community policing to transform many police services, despite some noble efforts to make it work, shows how the habits and practices of many decades of policing can be very difficult to change. However, the police should not be singled out in this, as they have been much more willing to at least try to change than have either the courts or the prison system. Here again, we would welcome research

Correspondence to: Rick Linden, Department of Sociology and Criminology, University of Manitoba, 66 Chancellors Circle, Winnipeg, MB R3T 2N2, Canada. E-mail: rick.linden@umanitoba.ca 
showing how best to ensure that new ways of dealing with society's problems become part of our normal way of doing business.

Finally, it is also worth noting that justice does not necessarily equate to the operations, capacities, and limitations of our more formal systems alone. Community justice and restorative practices have gained considerable traction in many jurisdictions, and some show considerable promise in both indigenous and non-indigenous environments. The Journal looks to continuing research and knowledge exchange to assist practitioners, policy makers, and local leaders to better understand how these methods might best contribute to achieving just solutions for victims, communities, and offenders, while also serving community safety and wellbeing in general.
CONFLICT OF INTEREST DISCLOSURES

The author declares no conflicts of interest.

\section{AUTHOR AFFILIATIONS}

*Department of Sociology and Criminology, University of Manitoba, Winnipeg, Manitoba.

REFERENCES

Malloy, J. (2018). CAPG Research and Policy Committee Survey. Ottawa, ON: Canadian Association for Police Governance. [Survey closed; contact communications@capg.ca ]

Winsa, P. (2018, July 26). Amid gun violence, stop-gap funding imposes constant turnover on gang-prevention programs (online article). Toronto Star. Retrieved from: https://www.thestar.com/news/gta/2018/07/22/ amid-gun-violence-stop-gap-funding-imposes-constant-turnover-on-gangprevention-programs.htm 